Perceptual and Motor Skills, 2011, 113, 2, 1-8. (C) Perceptual and Motor Skills 2011

\title{
RELATION BETWEEN PHYSICAL ACTIVITY AND ACADEMIC PERFORMANCE IN 3RD- YEAR SECONDARY EDUCATION STUDENTS ${ }^{1}$
}

\author{
JOSÉ MORALES \\ Facultat de Psicología \\ Ciències de l'Educació i l'Esport Blanquerna \\ Universitat Ramon Llull, Barcelona
}

\section{MANUEL GOMIS}

Centro de Investigación del Deporte Universidad Miguel Hernández, Elche

\author{
MAITE PELLICER-CHENOLL, XAVIER \\ GARCÍA-MASSÓ, ANA GÓMEZ
}

Departamento de Educación Física y Deportiva Universidad de Valencia

\section{LUIS-MILLÁN GONZÁLEZ}

\section{Departamento de Educación Física y Deportiva} Universidad de Valencia

Summary. - The main aim of this study was to analyze the relationship between the amount of physical activity and academic performance in 3rd-year secondary education students. The sample was taken from three secondary schools in the area of Barcelona. 284 students (158 girls, 126 boys) with an average age of $14.7 \mathrm{yr}$. participated. The International Physical Activity Questionnaire was used by students to self-report their amount of physical activity. Students' academic records were obtained for comparisons. Results showed that there was a linear relationship between academic performance and physical activity; nevertheless, there was a trend to stronger correlation when modeling the relationship between these variables with a quadratic equation. Further research should focus on whether academic performance and physical activity might be better explained with a second-order equation.

The lack of physical activity in children and adolescents has become a serious problem in society in the last few years. Physical inactivity is a risk factor in developing different diseases such as obesity and diabetes. There has been frequent speculation about the effects of physical activity on the school learning process in children and adolescents, and in the past there was a tendency to think that time devoted to nonacademic goals had a negative effect on academic performance (Lindner, 2002). In the last few years, studies have analyzed the relationship between physical activity and academic achievement from different perspectives, for example, evaluating participation in sports or physical activity programs as they relate to academic performance (McKenzie, Sallis, Kolody, \& Faucette, 1997; Sallis, McKenzie, Kolody, Lewis, Marshall, \& Rosengard, 1999). However, several well-designed studies about this issue have reached different conclusions, finding that physical activity has no relationship to academic performance (Sallis, et al., 1999; Daley \& Ryan, 2000; Tremblay, Inman, \& Wil-

${ }^{1}$ Address correspondence to José Morales Aznar, Facultat de Psicología, Ciències de l'Educació i l'Esport Blanquerna, Universitat Ramon Llull, C/ Císter, 34, 08022 Barcelona, Spain or e-mail (josema@blanquerna.url.edu). 
liams, 2000; Ahamed, MacDonald, Reed, Naylor, Liu-Ambrose, \& McKay, 2007), or showing that physical activity in students is associated with improvement in academic performance. Shephard (1997) and Shephard and Trudeau (2005) suggested that increasing the time spent in physical activity at school increased academic performance in comparison with students who had no additional activity. Symons, Cinelli, James, and Groff (1997) studied different behaviors related to health and learning, and concluded that physical exercise helps interneuronal connection and enhances concentration. Strong, Malina, Blimkie, Daniels, Dishman, Gutin, et al. (2005) acknowledged positive effects of physical activity on health, but doubted any direct relationship with higher cognitive performance. Dwyer, Sallis, Blizzard, Lazarus, and Dean (2001) developed a project with 7,961 Australian students, and Lindner (1999) with 4,690 students from Hong Kong. In both studies, physical activity habits were assessed with questionnaires, physical conditioning was tested, and students' academic records were obtained. Both studies found a significant, but small, correlation between academic outcomes and participation in more physical activities.

Referring to results obtained by other authors, it may be thought that the hours of practice and academic performance do not show a clear linear correlation. In other research, the hours spent in one activity do not always affect associated variables in a linear manner. An example could be the number of homework hours and academic performance (Cooper, Robinson, \& Patall, 2006), or in physiology, the increase of energy expenditure in cardiovascular health (Lee \& Paffenbarger, 1998). This kind of relationship could be posited between academic achievement and physical activity since both require effort and time commitment, but of a different quality. Perhaps this could explain why some studies have found that the academic performance achieved by students who are also elite athletes is similar to or lower than that of the general student population (Calabria, Garcia-Mas, Gimenez, Aguado, Cuartero, \& Pérez, 2003; Torregrosa, Sánchez, \& Cruz, 2004). All this suggests that there may be an optimum amount of physical activity that is related to higher academic performance. It was hypothesized that the relationship between academic performance and physical activity might not be linear, but follow a quadratic trend, due to the conflict in time and effort commitments.

\section{Method}

\section{Participants}

A total of 284 students (158 girls, 126 boys) took part in this study. All participants were 3rd-year students in secondary school with a mean age of $14.7 \mathrm{yr}$. The students came from a school population of three high schools in the metropolitan area of Barcelona (Catalonia). Students with a 
TABLE 1

Descriptive Statistics of the Sample's Anthropometric Variables

\begin{tabular}{|c|c|c|c|c|c|c|}
\hline & \multicolumn{2}{|c|}{ Boys $(n=126)$} & \multicolumn{2}{|c|}{ Girls $(n=158)$} & \multicolumn{2}{|c|}{ Total $(N=284)$} \\
\hline & $M$ & SEM & $M$ & SEM & $M$ & SEM \\
\hline Height, cm & 157.83 & 12.03 & 156.21 & 11.77 & 156.97 & 11.88 \\
\hline Weight, kg & 48.67 & 7.92 & 49.17 & 6.55 & 48.90 & 7.21 \\
\hline
\end{tabular}

physical or psychological disability were excluded from the study, as well as those that had been injured for more than a month during the previous academic year, and students with high truancy (i.e., more than $30 \% \mathrm{ab}$ sences). All students in the three high schools who fulfilled the inclusion criteria were included in the study. Table 1 shows the descriptive statistics for the anthropometric variables of participants.

All students and students' parents or legal guardians signed an informed consent form for their children's participation in the study. Educational authorities and Ramon Llull University's Research Ethics Committee in Barcelona approved the development of this study.

Physical Activity Measures

Physical activity carried out by every student was assessed with the International Physical Activity Questionnaire (IPAQ; Hallal \& Victoria, 2004; Hagströmer, Oja, \& Sjöström, 2006) in its short format. Results were transformed into units of metabolic index (MET) following guidelines as expressed in the IPAQ manual. ${ }^{2}$ Students were classified into three groups according to their self-reported physical activity. The Low activity group was made up of students with energy consumption lower than 1,000 METs, Moderate activity group by students with a metabolic rate between 1,000 and 2,500 METs, and finally the High activity group by students with more than 2,500 METs per week. This classification was established using interquartile values (i.e., 1,000 and 2,500 METs).

\section{Procedure}

The International Physical Activity Questionnaire was administered in a physical education session in the last academic term. Questionnaires were delivered with the same assessors always being present. Before filling in the questionnaires, participants were given a short explanation, in which they were told about: (i) answering items thinking about a typical week, rather than about the previous week, and (ii) the differences between vigorous and moderate activities.

Once the school year had finished, academic performance was as-

${ }^{2}$ Guidelines for Data Processing and Analysis of the International Physical Activity Questionnaire. (IPAQ) Revised November 2005. Available at: http://www.ipaq.ki.se/ scoring.pdf. Retrieved May 10, 2010. 
sessed by calculating the mean grades of each participant in the $10 \mathrm{sub}-$ jects of the 3rd year of secondary school. Since every subject had a mark ranging between 0 and 10, the academic performance score obtained also ranged between 0 and 10 . The academic records were provided by every high school's secretary office, with confidentiality of personal data being always guaranteed.

Analysis

The statistical analysis was carried out with SPSS software, Version 17 (SPSS, Inc., Chicago, IL, USA) and Origin Pro 8 (OriginLab, Northampton, MA, USA). Standard statistical methods were used to obtain the mean as a measure of central tendency and the typical standard error of the mean $(S E M)$ as a measure of dispersion. The variables were observed to comply with a normality test (Kolmogorov-Smirnov normality test) before the inferential analysis (academic achievement, $p=.07$; MET consumption, $p=.23)$. The results were analyzed in two different ways: the relationship between academic achievement and METs, and differences in academic achievement between quartile groups established according to MET consumption. The relationship between academic performance and MET was assessed by best fits of one- and two-degree polynomials (regardless of the quartile membership). Moreover, differences in academic achievement (dependent variable) among the groups (independent variable) were tested using a one-factor analysis of variance (ANOVA) for group (High, Moderate and Low activity). However, the assumption of homoscedasticity (Levene's test) was violated $(p<.001)$. Therefore, Welch's $F$ was used as it is a robust statistic in these conditions. Polynomial planned comparisons were used to test for trends in the data, as well as post hoc analysis with Games-Howell adjustment to assess which MET groups had different academic outcomes. This contrast was selected because it is the most suitable one when groups are not balanced and the assumption of homoscedasticity is not met. Statistical significance was set at $p<.05$.

\section{Results}

Polynomial fit analysis (see Fig. 1) showed that there was a significant linear relationship between the metabolic index (MET) and academic performance $(r=.31, p<.001 ; 95 \% C I=.20, .41)$. Nevertheless, the quadratic fitting reported a correlation not statistically significantly different $(r=.34, p<.001 ; 95 \% C I=.23, .44)$. There was a main effect for academic performance associated with physical activity $\left(F_{2,132.06}=10.48, p<.001\right.$; $\left.\omega^{2}=.08\right)$. Polynomial comparisons showed the existence of a squared trend $\left(F_{1,281}=14.59, p<.001\right.$; effect size $\left.r=.29\right)$. The pairwise comparisons showed greater academic performance $(p=.001)$ for the High activity group $(M=6.5 ; S E M=0.1)$ and Moderate activity group $(M=6.7 ; S E M=0.1)$ than 


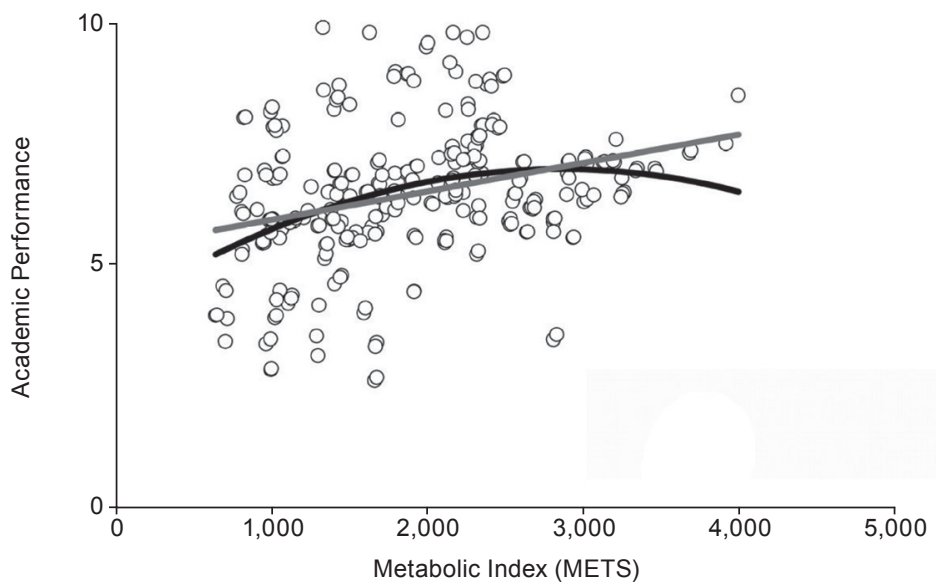

FIG. 1. Relationships between academic performance and metabolic rate (MET). The black curved line represents a squared relationship $\left(r=.34\right.$; slope $=2.04 \cdot 10^{-1}$ and $-3.58 \bullet 10^{-7}$; $p<.001)$ between the variables. The grey straight line represents a linear relationship $(r=.31$; slope $=5.87 \bullet 10^{-4} ; p<.001$ ) between academic performance and metabolic rate.

the Low activity group $(M=5.7 ; S E M=0.1)$. There were no differences between the Moderate activity group and the High activity group.

\section{Discussion}

Several prior cross-sectional studies have found a positive relationship between physical activity and academic performance (Lindner, 1999; Dwyer, et al., 2001). The present results also support this. Some authors have also suggested that practice of physical activity can promote improvement in mental functioning and cognitive development (Davis, Tomporowski, Boyle, Waller, Miller, Naglieri, et al., 2007; Tomporowski, Davis, Miller, \& Naglieri, 2008; Trudeau \& Shephard, 2008). It has even been found that isolated physical activity sessions improve reading comprehension, attention, and academic performance (Hillman, Pontifex, Raine, Castelli, Hall, \& Kramer, 2009). There may be various reasons for this improvement in academic performance (Shafer \& Armer, 1972; Symons, et al., 1997; Morales, 2004): athletes with higher performance are immersed in a culture of effort, persistence, and competitiveness, which they could apply to the academic field; sports activity increases self-esteem and self; sports activity increases socialization and therefore academic performance; increased physical fitness results in an increase in mental performance; physical activity improves brain oxygenation, resulting in higher capacity for concentration and improvement in cognitive capacities.

Apparently this is the first study to establish a second-degree relationship between academic performance and amount of physical activity. 
There was a statistically significant linear correlation between the variables of physical activity and academic outcome with a small magnitude $(r=.31)$. A squared adjustment indicated a possibly better fit with a second-order polynomial; nevertheless, that result should be considered preliminary. Such a trend to a second-order relationship between academic performance and physical activity could mean that a certain amount of weekly physical activity might prove optimal for academic performance.

The results support prior research showing that physical activity practice at vigorous to moderate intensity is related to better cognitive performance. Moreover, students who reported high activity were not significantly different on academic performance from those reporting moderate activity. Although the sample size was large, testing for a squared relationship would require an objective measure of MET, such as accelerometry or gas analysis, and a broader range of activity among respondents. Furthermore, assessing cognitive function as a covariate has been recommended in this type of study (California Department of Education, 2001; Castelli, Hillman, Buck, \& Erwin, 2007). One can conclude that physical activity practice is positively related to academic performance- and there is some evidence that the relationship between the two variables could be second-order, i.e., there could be an optimal amount of physical activity for best academic performance. Other likely sources of confounds should be controlled in future research so that robust information about optimal physical activity can be suggested for implementation in schools.

\section{REFERENCES}

Ahamed, Y., MacDonald, H., Reed, K., Naylor, P. J., Liu-Ambrose, T., \& McKay, H. (2007) School-based physical activity does not compromise children's academic performance. Medicine E Science in Sports E Exercise, 39, 371-376.

Calabria, E., Garcia-Mas, A., Gimenez, R., Aguado, F. J., Cuartero, J., \& Pérez, P. (2003) Sueño, descanso y rendimiento en jóvenes deportistas de competición. Revista de Psicologia del Deporte, 12, 181-196.

California Department of Education (CDE). (2001) California Physical Fitness Test: report to the governor and legislature. Sacramento, CA: California Department of Education, Standards and Assessment Division.

Castelli, D. M., Hillman, C. H., Buck, S. M., \& Erwin, H. E. (2007) Physical fitness and academic achievement in third- and fifth-grade students. Journal of Sport and Exercise Psychology, 29, 239-252.

Cooper, H., Robinson, J. C., \& Patall, E. A. (2006) Does homework improve academic achievement? A synthesis of research, 1987-2003. Review of Educational Research, $76,1-62$.

Daley, A. J., \& Ryan, J. (2000) Academic performance and participation in physical activity by secondary school adolescents. Perceptual and Motor Skills, 91, 531534. 
Davis, C. L., Tomporowski, P. D., Boyle, C. A., Waller, J. L., Miller, P. H., Naglieri, J. A., \& Gregoski, M. (2007) Effects of aerobic exercise on overweight childen's cognitive functioning: a randomized controlled trial. Research Quarterly for Exercise and Sport, 78, 510-519.

Dwyer, T., Sallis, J., Blizzard, L., Lazarus, R., \& Dean, K. (2001) Relation of academic performance to physical activity and fitness in children. Pediatric Exercise Science, $13,225-237$.

Hagströmer, M., Oja, P., \& Sృöström, M. (2006) The International Physical Activity Questionnaire (IPAQ): a study of concurrent and construct validity. Public Health Nutrition, 9, 755-762.

Hallal, P. C., \& Victoria, C. G. (2004) Reliability and validity of the International Physical Activity Questionnaire (IPAQ). Medicine E Science in Sports E Exercise, 36, 556-566.

Hillman, C. H., Pontifex, M. B., Raine, L. B., Castelli, D. M., Hall, E. E., \& Kramer, A. F. (2009) The effect of acute treadmill walking on cognitive control and academic achievement in preadolescent children. Neuroscience, 159, 1044-1054.

Lee, I. M., \& Paffenbarger, R. S. (1998) Physical activity and stroke incidence: the Harvard Alumni Health Study. Stroke, 29, 2049-2054.

LINDNER, K. (1999) Sport participation and perceived academic performance of school children and youth. Pediatric Exercise Science, 11, 129-143.

LINDNER, K. J. (2002) The physical activity participation-academic performance relationship revisited: perceived and actual performance and the effect of banding (academic tracking). Pediatric Exercise Science, 14, 155-169.

McKenzie, T. L., Sallis, J. F., Kolody, B., \& Faucette, F. N. (1997) Long-term effects of a physical education curriculum and staff development program: SPARK. Research Quarterly for Exercise and Sport, 68, 280-291.

Morales, J. (2004) Relación entre el desarrollo motor y el desarrollo intelectual: un estudio empírico. Apunts: Educación Física y Deportes, 77, 34-41.

Sallis, J. F., McKenzie, T. L., Kolody, B., Lewis, M., Marshall, S., \& Rosengard, P. (1999) Effects of health-related physical education on academic achievement: project SPARK. Research Quarterly for Exercise and Sport, 70, 127-134.

Shafer, W. E., \& Armer, J. M. (1972) Athletes are not inferior students. In R. N. Singer (Ed.), Readings in motor learning. Philadelphia: Lea and Febiger. Pp. 102-111.

Shephard, R. J. (1997) Curricular physical activity and academic performance. Pediatric Exercise Science, 9, 113-126.

Shephard, R. J., \& Trudeau, F. (2005) Lessons learned from the Trois-Rivières Physical Education Study: a retrospective. Pediatric Exercise Science, 17, 112-123.

Strong, W. B., Malina, R. M., Blimkie, C. J., Daniels, S. R., Dishman, R. K., Gutin, B., Hergenroeder, A. C., Must, A., Nixon, P. A., Pivarnik, J. M., Rowland, T., Trost, S., \& Trudeau, F. (2005) Evidence-based physical activity for school-age youth. Journal of Pediatrics, 146, 732-737.

Symons, C. W., Cinelli, B., James, T. C., \& Groff, P. (1997) Bridging student health risks and academic achievement through comprehensive school health programs. Journal of School Health, 67, 220-227.

Tomporowski, P. D., Davis, C. L., Miller, P. H., \& Naglieri, J. A. (2008) Exercise and children's intelligence, cognition, and academic achievement. Educational Psychology Review, 20, 111-131. 
Torregrosa, M., SÁnchez, X., \& Cruz, J. (2004) El papel del psicólogo del deporte en el asesoramiento académico-vocacional del deportista de élite. Revista de Psicologia del Deporte, 13, 215-227.

Tremblay, M. S., Inman, J. W., \& Williams, D. (2000) The relationship between physical activity, self-esteem, and academic achievement in 12-year-old children. Pediatric Exercise Science, 12, 312-323.

Trudeau, F., \& Shephard, R. J. (2008) Physical education, school physical activity, school sports, and academic performance. International Journal of Behavioral Nutrition and Physical Activity, 5, 10.

Accepted September 8, 2011. 